\title{
Resistance of Castanea mollissima Shuhe- WYL strain to Dryocosmus kuriphilus and its molecular mechanism
}

\author{
G.M. Geng, C.C. Zhu and J.Y. Zhou \\ Institute of Botany, Jiangsu Province and The Chinese Academy of Sciences, \\ Nanjing, China \\ Corresponding author: G.M. Geng \\ E-mail: ggmin123456@163.com
}

Genet. Mol. Res. 14 (3): 11456-11461 (2015)

Received January 29, 2015

Accepted June 8, 2015

Published September 25, 2015

DOI http://dx.doi.org/10.4238/2015.September.25.12

ABSTRACT. The resistance of Castanea mollissima Shuhe-WYL strain to Dryocosmus kuriphilus and its molecular mechanism were examined. The larvae of $D$. kuriphilus were inoculated on the Shuhe-WYL and Qingzha strains, and mortality was observed and compared; the relative mRNA content of the OsCDPK2, receptor-like protein, OsNAC6 protein, $K H$ domain protein, RNAbinding protein, and the $b H L H$ genes was detected using real-time polymerase chain reaction, and then compared between the Shuhe-WYL and Qingzha strains. Phenylalanine ammonia-lyase content was detected by western blotting and compared between the inoculated Shuhe-WYL, non-inoculated ShuheWYL, and inoculated Qingzha strains. The mortalities of larvae inoculated on the bud, bracteal leaf, and cardiac lobe were lower in Shuhe-WYL than Qingzha at 48 and $96 \mathrm{~h}$ after inoculation; the contents of OsCDPK2, receptor-like protein, OsNAC6 protein, and $b H L H$ in the cardiac lobe were higher in Shuhe-WYL than in Qingzha at $96 \mathrm{~h}$ after inoculation, but $\mathrm{KH}$ domain protein and RNA-binding protein were not significantly different. The content of phenylalanine ammonialyase in the cardiac lobe was higher in inoculated and non-inoculated ShuheWYL compared to inoculated Qingzha at 15, 30, 45, and 60 days, and higher in inoculated Shuhe-WYL than in non-inoculated Shuhe-WYL at 15, 30, 45, 
and 60 days. The content of phenylalanine ammonia-lyase in the cardiac lobe of inoculated Shuhe-WYL had no significant difference between at 60 and at 45 days; and was higher at 60 and 45 days than at 30 and 15 days; and was higher at 30 days than at 15 days $(60 \approx 45>30>15$ days). The $C$. mollissima Shuhe-WYL strain was resistant to $D$. kuriphilus; high expression of OsCDPK2, receptor-like protein, OsNAC6 protein, and $b H L H$ and phenylalanine ammonialyase may explain the mechanism.

Key words: Castanea mollissima; Dryocosmus kuriphilus; Resistance; Phenylalanine ammonia-lyase

\section{INTRODUCTION}

Dryocosmus kuriphilus (chestnut gall wasp), belongs to Hymenoptera, Cynipidae and is an important pest in chestnuts. The larvae of $D$. kuriphilus infest the bud of the chestnut, which can wither the bud. The Castanea mollissima (Chinese chestnut) Shuhe-WYL strain is a hybrid of the wild CG-200 and Shuhe strains. During the course of breeding, the C. mollissima Shuhe-WYL strain showed resistance to $D$. kuriphilus (Zhang et al., 2000). Phenylalanine ammonia-lyase (PAL) is a key enzyme that catalyze sphenyl propanoid metabolism. The products of phenyl propanoid metabolism include the phenols phytoalexin and isoflavones phytoalexin, which positively influence the resistance to pests in plants (Kumar and Ellis, 2001). In the phenylpropanoid pathway, the OsCDPK2, receptor-like protein, OsNAC6 protein, KH domain protein, RNA-binding protein, and bHLH genes are important in the production and activity of PAL (Zhao et al., 2001; MacDonald and D'Cunha, 2007; Pina and Errea, 2008). Additionally, they are critical for the production of phytoalexin.

In this study, we investigated the resistance of the C. mollissima Shuhe-WYL strain to $D$. kuriphilus and detected the relative content of mRNA of genes potentially related to the resistance and content of endogenous PAL. The aim of this study was to explain the mechanism of $C$. mollissima Shuhe-WYL strain resistance to $D$. kuriphilus and provide useful information for breeding chestnut strains with resistance to pests.

\section{MATERIAL AND METHODS}

\section{Materials}

\section{Chestnut strains}

The experimental strain used was the C. mollissima Shuhe-WYL strain, while the control strain was the C. mollissima Qingzha strain. The experimental field was in Jiangsu Province, China, which is the main habitat of the Chinese chestnut Shuhe-WYL strain. The experimental and control strains were grown in different gardens of the experimental field at the same time and infestation of $D$. kuriphilus was prevented. During the experiment, the experimental and control strains were given routine field management and insecticides were not used.

\section{D. kuriphilus for experiments}

The egg of $D$. kuriphilus was collected from the Qingzha strain in the field and was then incubated and a bred in the laboratory. The larvae of the F2 generation were used in the experiment. 


\section{Methods}

\section{Infestation experiment}

The underyearling bud, bracteal leaf, and cardiac lobe of the Shuhe-WYL strain and Qingzha strain each weighing $4 \mathrm{~g}$ were randomly collected in the experimental field and soaked for $12 \mathrm{~h}$ in $2 \%$ sodium hypochlorite, washed 5 times with sterile water, and placed into test tubes after air drying. For both the Shuhe-WYL strain and Qingzha strain, 45 test tubes were used (15 for the bud, 15 for the bracteal leaf, and 15 for the cardiac lobe). Each test tube was inoculated with 12 larvae of $D$. kuriphilus, and all larvae were the same age. The test tube was bound with carbasus and prostrated. The surviving larvae were evaluated at 48 and $96 \mathrm{~h}$ after inoculation.

\section{Detection of the relative $m R N A$ content of the OsCDPK2, receptor-like protein, OsNAC6 protein, $\mathrm{KH}$ domain protein, RNA binding protein, and bHLH genes}

Total RNA was extracted from the cardiac lobe of the Shuhe-WYL strain and Qingzha strain, which was inoculated for $96 \mathrm{~h}$ with the larvae of $D$. kuriphilus, and then reverse-transcribed into cDNA to be used as a template for real-time polymerase chain reaction. Both the Shuhe-WYL and Qingzha strains included 15 samples. The $20-\mu \mathrm{L}$ reaction system contained $10 \mu \mathrm{L}$ SYBR Premix ExTaqTM, $1 \mu \mathrm{L}$ upstream primer, $1 \mu \mathrm{L}$ down stream primer, $1 \mu \mathrm{L}$ cDNA, and $7 \mu \mathrm{L}$ deionized water. Primer sequences and polymerase chain reaction product sizes are shown in Table 1 . The reaction conditions were pre-denaturation at $95^{\circ} \mathrm{C}$ for $3 \mathrm{~min}$, denaturation for $95^{\circ} \mathrm{C}$, for $30 \mathrm{~s}$, and renaturation at $55^{\circ} \mathrm{C}$, for $10 \mathrm{~s}$ for 40 cycles. Finally, the relative content of mRNA was analyzed using the $2^{-\Delta \Delta C t}$ method (using $\beta$-actin as an internal reference).

Table 1. Sequence of the primers and the size of PCR products.

\begin{tabular}{|c|c|c|}
\hline Gene & Sequence of primer $\left(5^{\prime}-3^{\prime}\right)$ & Size (bp) \\
\hline OsCDPK2 & $\begin{array}{l}\text { F: ATCCAGAGGCAAACGGAGC } \\
\text { R: CACATGGCAACATCTAACAG }\end{array}$ & 107 \\
\hline Receptor-like protein & $\begin{array}{l}\text { F: CGTCGCTCCAAATACACCAA } \\
\text { R: CAGCGAAACATCCCCATCT }\end{array}$ & 130 \\
\hline OsNAC6 protein & $\begin{array}{l}\text { F: GCCAGCGGTGAGAAAGGA } \\
\text { R: CAACCCTCCGACCATCAGTT }\end{array}$ & 80 \\
\hline $\mathrm{KH}$ domain protein & $\begin{array}{l}\text { F: GCGCTCATCTTCTTCCGAAT } \\
\text { R: CGCGGTCGTGGTTATGTG }\end{array}$ & 126 \\
\hline RNA binding protein & $\begin{array}{l}\text { F: CTGGATCCAACAATGAGC } \\
\text { R: ATCAAGATGGAGACCCA }\end{array}$ & 84 \\
\hline$b H L H$ & $\begin{array}{l}\text { F: AGCGGGCGCAGATGAC } \\
\text { R: CGTTCATGCACTCGCTGAA }\end{array}$ & 115 \\
\hline$\beta$-actin & $\begin{array}{l}\text { F: CACTCTTCCAGCCTTCCTTC } \\
\text { R: GGATGTCCACGTCACACTTC }\end{array}$ & 92 \\
\hline
\end{tabular}

\section{Detection of PAL content by western blotting}

The cardiac lobe of the Shuhe-WYL strain and Qingzha strain was inoculated with 12 larvae on each leaf of $D$. kuriphilus. One hundred tagged leaves of the Shuhe-WYL and Qingzha strains were inoculated with the larvae of $D$. kuriphilus. At 15, 30, 45, and 60 days after inoculation, 15 tagged leaves of the Shuhe-WYL and Qingzha strains were randomly collected, while 15 leaves (cardiac lobes) of the Shuhe-WYL strain that had not been infested by the larvae were also 
randomly collected. Total protein was extracted from the cardiac lobe. The BCA method was used for protein quantification. First, $30 \mu \mathrm{g}$ protein was mixed with sample buffer. The sample was then boiled for $5 \mathrm{~min}$ and separated by sodium dodecyl sulfate-polyacrylamide gel electrophoresis, and the percentage of the gel was $12 \%$. The protein was transferred to nitrocellulose membranes and then blocked for $1 \mathrm{~h}$ with Tris-buffered saline-Tween 20containing $50 \mathrm{~g} / \mathrm{L}$ dried skim milk at room temperature. Rabbit anti-PAL and mouse anti- $\beta$-actin antibodies were added to the mixture, and the mixture was incubated at $4^{\circ} \mathrm{C}$ overnight. The mixture was washed 3 times with Tris-buffered saline-Tween 20 , and goat anti-rabbit and goat anti-mouse secondary antibodies labeled with horseradish peroxidase were added. The mixture was incubated for $1 \mathrm{~h}$ at room temperature and then washed 3 times with Tris-buffered saline-Tween 20. Finally, the samples were visualized using electrochemiluminescence.

\section{Statistical analysis}

The mortality of the larvae of $D$. kuriphilus, the relative content of mRNA of the OsCDPK2, receptor-like protein, OsNAC6 protein, KH domain protein, RNA-binding protein, and $b H L H$ genes, and the content of PAL were compared using Student $t$-tests. Statistical analysis was performed using SPSS version 17.0 (SPSS, Inc., Chicago, IL, USA). Significance was set at $P<0.05$.

\section{RESULTS}

\section{Mortality of $D$. kuriphilus larvae}

The mortalities of the $D$. kuriphilus larvae are shown in Table 2. The mortalities of $D$. kuriphilus larvae inoculated on the bud, bracteal leaf, and cardiac lobe were lower in the ShuheWYL strain than in the Qingzha strain at $48 \mathrm{~h}$ after inoculation $(t=20.042, \mathrm{P}=0.000 ; t=14.548$, $\mathrm{P}=0.000 ; t=24.547, \mathrm{P}=0.000$ ), and the mortalities of $D$. kuriphilus larvae inoculated on the bud, bracteal leaf, and cardiac lobe were also lower in the Shuhe-WYL strain than in the Qingzha strain at $96 \mathrm{~h}$ after inoculation $(t=27.384, \mathrm{P}=0.000 ; t=29.152, \mathrm{P}=0.000 ; t=28.387, \mathrm{P}=0.000)$.

Table 2. Mortalities of the larvae of Dryocosmus kuriphilus inoculated in the bud, bracteal leaf, and cardiac lobe of the Shuhe-WYL and Qingzha strains at 48 and $96 \mathrm{~h}$ after inoculation.

\begin{tabular}{llcrr}
\hline Strain & Inoculating position & No. of test tubes & Mortality at 48 h (\%) & Mortality at 96 h (\%) \\
\hline Shuhe-WYL & Bud & 15 & $33.1 \pm 4.48$ & $79.5 \pm 5.25$ \\
& Bracteal leaf & 15 & $23.5 \pm 4.21$ & $67.2 \pm 5.08$ \\
\multirow{3}{*}{ Qingzha } & Cardiac lobe & 15 & $31.5 \pm 4.57$ & $77.6 \pm 6.02$ \\
& Bud & 15 & $4.2 \pm 2.03$ & $8.7 \pm 3.15$ \\
& Bracteal leaf & 15 & $3.7 \pm 1.98$ & $3.9 \pm 2.12$ \\
\hline
\end{tabular}

Relative mRNA content of OsCDPK2, receptor-like protein, OsNAC6 protein, $\mathrm{KH}$ domain protein, RNA-binding protein, and $b H L H$ genes

The relative mRNA content of the OsCDPK2, receptor-like protein, OsNAC6 protein, KH domain protein, RNA-binding protein, and bHLH genes is shown in Table 3 . The relative content of the OsCDPK2, receptor-like protein, OsNAC6 protein, and $b H L H$ genes were higher in the ShuheWYL strain than in the Qingzha strain $(t=11.028, \mathrm{P}=0.000 ; t=12.257, \mathrm{P}=0.000 ; t=3.056, \mathrm{P}$ 
$=0.012 ; t=14.238, \mathrm{P}=0.000)$. The relative contents of the $K H$ domain protein and $R N A$-binding protein genes were not significantly different between the Shuhe-WYL and the Qingzha strains $(t=$ $0.034, \mathrm{P}=0.973 ; t=0.158, \mathrm{P}=0.694)$.

Table 3. Relative content of mRNA of the OsCDPK2, receptor-like protein, OsNAC6 protein, KH domain protein, RNA-binding protein, and $b H L H$ genes in the cardiac lobe of the Chinese chestnut Shuhe-WYL strain and Chinese chestnut Qingzha strain at $96 \mathrm{~h}$ after inoculation.

\begin{tabular}{lccrr}
\hline Gene & No. of samples & \multicolumn{2}{c}{ Relative content of mRNA } & $t$ \\
\cline { 3 - 4 } & & Shuhe-WYL & Qingzha & \\
\hline OsCDPK2 & 15 & $0.82 \pm 0.24$ & $0.23 \pm 0.17$ & 11.028 \\
Receptor-like protein & 15 & $0.77 \pm 0.18$ & $0.15 \pm 0.26$ & 12.257 \\
OsNAC6 protein & 15 & $0.35 \pm 0.22$ & $0.22 \pm 0.34$ & 3.056 \\
KH domain protein & 15 & $0.76 \pm 0.25$ & $0.74 \pm 0.27$ & 0.000 \\
RNA binding protein & 15 & $0.34 \pm 0.31$ & $0.36 \pm 0.29$ & 0.012 \\
bHLH & 15 & $0.67 \pm 0.16$ & $0.13 \pm 0.14$ & 0.158 \\
\hline
\end{tabular}

\section{Content of PAL}

PAL content in the cardiac lobe was higher in the inoculated Shuhe-WYL strain and noninoculated Shuhe-WYL strain than in the inoculated Qingzha strain at the same time points (t15, $30,45,60=15.254,14.027,10.157,9.846$, and P15, 30, 45, $60=0.000$ for inoculated Shuhe-WYL strain vs Qingzha strain; t15, 30, 45, $60=7.236,6.905,5.269$, and 4.985, and P15, 30, 45, $60=$ 0.000 for the non-inoculated Shuhe-WYL strain vs Qingzha strain), and PAL content in the cardiac lobe was higher in the inoculated Shuhe-WYL strain than non-inoculated Shuhe-WYL strain at the same time points $(\mathrm{t} 15,30,45,60=6.245,5.458,5.024$, and 5.921 and $\mathrm{P} 15,30,45,60=0.000$ for the inoculated Shuhe-WYL strain vs non-inoculated Shuhe-WYL strain). PAL content in the cardiac lobe of the inoculated Shuhe-WYL strain was 60 days $\approx 45$ days $>30$ days $>15$ days (t60 vs 15 $=4.925, \mathrm{P} 60$ vs $15=0.000 ; \mathrm{t} 60$ vs $30=2.985, \mathrm{P} 60$ vs $30=0.024 ; \mathrm{t} 60$ vs $45=0.186, \mathrm{P} 60$ vs 45 $=0.648$; $\mathrm{t} 45$ vs $15=5.128$, P45 vs $15=0.000 ; \mathrm{t} 45$ vs $30=3.041, \mathrm{P} 45$ vs $30=0.011 ; \mathrm{t} 30$ vs $15=$ 2.874, P30 vs $15=0.029$ ) (Table 4).

Table 4. Content of PAL in the cardiac lobe of inoculated the Shuhe-WYL strain, non-inoculated Shuhe-WYL strain, and Inoculated Qingzha strain on 15, 30, 45, and 60 days after inoculation.

\begin{tabular}{lcccc}
\hline Strain & 15 days & 30 days & 45 days & 60 days \\
\hline Inoculated Shuhe-WYL & $46.22 \pm 4.035$ & $65.24 \pm 4.574$ & $78.45 \pm 5.147$ & $76.55 \pm 4.834$ \\
Non-inoculated Shuhe-WYL & $21.46 \pm 6.023$ & $33.79 \pm 3.846$ & $40.12 \pm 6.249$ & $38.67 \pm 5.748$ \\
Inoculated Qingzha & $8.75 \pm 5.146$ & $13.67 \pm 4.029$ & $24.48 \pm 4.249$ & $23.59 \pm 3.825$ \\
\hline
\end{tabular}

\section{DISCUSSION}

$D$. kuriphilus mainly harms the bud of chestnut. The newborn larva of $D$. kuriphilus can infest the bud, leading to branch death. In this study, we evaluated the resistance of the bud, bracteal leaf, and cardiac lobe of the Chinese chestnut Shuhe-WYL strain to the larvae of $D$. kuriphilus. The results showed that most of the larvae inoculated on the Shuhe-WYL strain had died by $96 \mathrm{~h}$; the mortality rate was higher than that in the control strain. This indicates that the Shuhe-WYL strains are effectively resistant to damage caused by $D$. kuriphilus.

PAL is a key enzyme that catalyzes phenylpropanoid metabolism and is very important 
for the resistance of plants to pests. When plants are infested by pests, the content and activity of endogenous PAL increases, accelerating phenylpropanoid metabolism. This results in increased phytoalexin production, including lignin and pyrocatechol. Pyrocatechol has been shown to be positively correlated with the resistance of chestnut to $D$. kuriphilus, and lignin can increase the lignification of the gallae endosporium of $D$. kuriphilus, limiting the feeding of $D$. kuriphilus larvae. Several studies have shown that the OsCDPK2, receptor-like protein, OsNAC6 protein, KH domain protein, RNA-binding protein, and $b H L H$ genes are correlated with the production and activity of PAL. In this study, we found that the relative mRNA content of the OsCDPK2, receptor-like protein, OsNAC6 protein, and bHLH genes was higher in the Shuhe-WYL strain than in the Qingzha strain inoculated for $96 \mathrm{~h}$, and the content of PAL was higher in the inoculated Shuhe-WYL strain and non-inoculated Shuhe strain than in the Qingzha strain. PAL content increased with infestation time in the inoculated Shuhe-WYL strain. These results may explain the mechanism of the resistance of the Shuhe-WYL strain to $D$. kuriphilus.

In summary, the $C$. mollissima Shuhe-WYL strain was resistant to $D$. kuriphilus; the high expression of the OsCDPK2, receptor-like protein, OsNAC6 protein, and bHLH genes and PAL may explain the mechanism. However, other factors also lead to increased PAL expression, such ashypothermia, perfunctory injuries, growth hormone, aethylenum, and infection (Hu et al., 2011). Therefore, further studies of the mechanism should be conducted.

\section{Conflicts of interest}

The authors declare no conflict of interest.

\section{ACKNOWLEDGMENTS}

Research supported by The Central Government Forestry Science and Technology Demonstration Projects [\#(2012)TK29]. The funder had no role in study design, data collection and analysis, decision to publish, or preparation of the manuscript.

\section{REFERENCES}

Hu GS, Jia JM, Hur YJ, Chung YS, et al. (2011). Molecular characterization of phenylalanine ammonia lyase gene from Cistanche deserticola. Mol. Biol. Rep. 38: 3741-3750.

Kumar A and Ellis BE (2001). The phenylalanine ammonia-lyase gene family in raspberry. Structure, expression, and evolution. Plant Physiol. 127: 230-239.

MacDonald MJ and D'Cunha GB (2007). A modern view of phenylalanine ammonia lyase. Biochem. Cell. Biol. 85: 273-282.

Pina $A$ and Errea P (2008). Differential induction of phenylalanine ammonia-lyase gene expression in response to in vitro callus unions of Prunus spp. J. Plant Physiol. 165: 705-714.

Zhang DL, Quantick PC and GrigorJM (2000). Changes in phenolic compounds in Litchi (Litchi chinensis Sonn.) fruit during postharvest storage. Postharvest Biol. Tec. 19: 165-172.

Zhao J, Zhu WH and Hu Q (2001). Enhanced catharanthine production in catharanthusroseus cell cultures by combined elicitor treatment in shake flasks and bioreactors. Enzyme Microb. Tech. 28: 673-681. 